Departamento de Zoologia Médica e Parasitologia

Diretor: Prof. Dr. Z. Vaz

\title{
SOBRE UMA NOVA ESPÉCIE DO GÊNERO CAPILLARIA E OBSERVAÇÕES HELMINTOLÓGICAS
}

POR

\author{
T. L. Araujo e Y. Gandra \\ Assistente
}

Com estampas vI - VII

Graças à gentileza do prof. CARINI tivemos a oportunidade de autopsiar um exemplar de Tropidurus torquatus torquatus (WIED, 1860) proveniente de Goiás, no intestino do qual encontramos numerosos exemplares machos e fêmeas de um Nematoda - Capillarinae que julgamos novo e cuja descrição faremos a seguir.

Agradecemos ao prof. CARINI o Lacertilio que nos enviou e ao Dr. Afranio do Amaral a determinação do mesmo. Dedicamos a espécie ora descrita aos eminentes helmintologistas do Instituto Oswaldo Cruz, Drs. H. Lent e J. T. Freitas.

\section{Capillaria freitaslenti n. sp.}

(figs. 6-9) Est. VI

Comprimento: - macho: 6,6 mm. - 9,2 mm.; fêmea: 10,3 mm. - 14,0 mm.

Largura: - macho: 0,032 mm.; fêmea: 0,048 mm.

Corpo de cutícula branca, lisa, sem faixas bacilares laterais. Boca ligeiramente saliente, circular, nua. Esôfago medindo 2,4 mm. 4,9 mm. de comprimento. Porção muscular com 0,355 mm. Anel nervoso distando $0,134 \mathrm{~mm}$. da extremidade anterior.

Fêmea com vulva provida de dois lábios salientes, abrindo-se à $0,124 \mathrm{~mm}$. - 0,172 mm. da terminação do esôfago. Vagina com 0,331 mm. de comprimento. Utero com ovos medindo $0,053 \mathrm{~mm}$. por 0,024 mm.. Extremidade posterior romba. Anus terminal. Relação entre a porção anterior e a posterior $1: 1,3$.

Macho com bainha do espículo espinhosa, medindo 0,008 mm. de largura. Espículo não observado. Extremidade caudal com bolsa membranosa nítida medindo $0,041 \mathrm{~mm}$. de largura, quando completamente aberta. Bolsa com um par de papilas conspícuas, recurvadas para dentro. Cloaca terminal. Junção do tubo intestinal com o genital à $1,23 \mathrm{~mm}$. - 1,35 mm. da extremidade posterior. Relação entre as porções anterior e posterior $1: 1,2$. 
tus (WIED, 1860).

Habitat - Intestino delgado de Tropidurus torquatus torqua-

Proveniência: Goiás.

Tipos e cotipos no Laboratório de Zoologia Médica e Parasitologia da Faculdade de Medicina Veterinária da Universidade de São Paulo.

Variações do ovário de Fasciola he patica L., 1758.

(figs. 1 - 5)

Pretendemos assinalar mais uma vez algumas variações ovarianas de Fasciola hepatica L., 1758, já que tais modificações devem ser sempre mostradas e levadas em consideração como nos ponderou o prof. L. Travassos. O mesmo prof., em 1926, no Boletim Biológico já chamara a atenção para uma série de anomalias do ovário de Fasciola hepatica por ele observadas, variações essas «que podiam conduzir os helmintologistas a erros se fossem observadas isoladamente em trematóides menos comuns». O que ora observamos muito se assemelha ao que o prof. L. Travassos em 1926 descreveu e figurou no fascículo 3 do Boletim Biológico.

Lacaz de Moraes publicou em 1933 observações sobre anomalias nas glândulas vitelinas da mesma espécie verificadas em material do Departamento de Parasitologia da Faculdade de Medicina de São Paulo.

Temos a impressão de que as anomalias no ovário do grande e conhecido trematoide são bastante comuns, isto porque num lote de 30 exemplares encontramos 4 anômalos, o que dá uma percentagem de $13,3 \%$. Todos os exemplares que examinamos provieram de bovinos abatidos nos matadouros de São Paulo.

Num exemplar (fig. 1) nota-se o tronco principal dando dois ramos que se dirigem para lados opostos. Um deles ramifica-se intensamente enquanto o outro após um trajeto de $0,83 \mathrm{~mm}$. bifurca-se, terminando por dois curtos ramos. Noutro exemplar os dois ramos dirigem-se tambem para lados opostos (fig. 2): um ramifica-se e o outro sem se ramificar, termina, depois de um trajeto de $1,6 \mathrm{~mm}$..

Num terceiro exemplar (fig. 3) os dois ramos primitivos dirigem-se para lados opostos e se ramificam dando a impressão da existência de dois ovários. No último exemplar de Fasciola hepatica com variações no ovário nota-se um tronco único primitivamente que depois se bifurca. Seus ramos dirigem-se para lados contrários onde se ramificam de maneira aproximadamente igual. Essa disposição nos oferece um aspeto interessante, quase simétrico. 
Reproduzimos para facilidade de comparação um ovário normal de Fasciola hepatica (fig. 5).

Sterrharus branchialis StUNKARD et NigRell, 1934

(fig. 10)

H. W. Stunkard e R. F. Nigrelli descreveram sob a denominação supra em 1934, um trematoide encontrado nas brânquias e no intestino de «peixe espada». (Trichiurus lepturus) pescado próximo de Long Island, N. Y.

Tivemos ocasião de encontrar numerosos exemplares do mesmo trematoide no intestino de peixe da mesma espécie, pescado em Santos (Atlântico Sul). Achamos de interesse assinalar o fato, por nos parecer não ter sido ainda o $S$. branchialis incluido na lista dos componentes da nossa fauna helmintológica e transcrevemos as medidas verificadas em exemplares que encontramos:

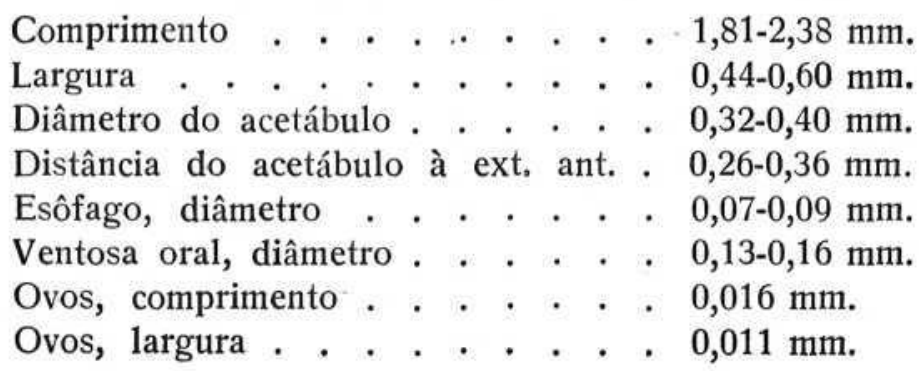

\section{BIBLIOGRAFIA}

Moraes, L. - 1933 - Anomalias das glândulas vitelinas da «Fasciola hepatica». Ann. Paul. Med. Cir, 24.

Stunkard, H. W. - Nigrelli, R. F. - 1934 - Observations on the genus Sterrhurus Looss, with a description of Sterrhurus branchialis sp. nov. (Trematoda, Hemiuridae). Biol. Bull, 67 (3) 534/43.

Teixeira de Freitas, J. F. - Lent, H. - 1935 - «Capillariinae». de animais de sangue frio (Nematoda: Trichuroidea). Mem. Ins. Osw. Cruz, 30 (2) $123 / 56$.

Travassos, L. - 1926 - Anomalias do ovário da «Fasciola hepatica» L. 1758. Bol. Biol. (3) 55/8. 


\section{EXPLICAÇÃO DAS FIGURAS}

\section{Estampa VI}

Figs. 1, 2, 3 e 4 - Ovários de $F$. hepatica com anomalias.

Fig. 5-Ovário normal de $F$. hepatica.

\section{Estampa VII}

Fig. $6-C$. freitaslenti: macho, extremidade posterior, vista de frente. Fig. $7-C$. freitaslenti: macho, extremidade posterior, vista de lado. Fig. $8-C$. freitaslenti: fêmea, região vulvar.

Fig. $9-C$. freitaslenti: fêmea, extremidade posterior, vista de frente. Fig. 10 - Sterrhurus branchialis. 
T. L. Araujo e Y. Gandra, Nova Capillaria e observações Helmintológicas.

1

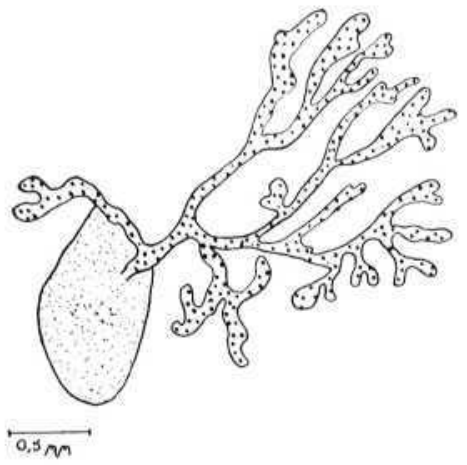

Rev. Fac. Med. Vet. S. Paulo, Vol. 2, fage, 1

Est. VI

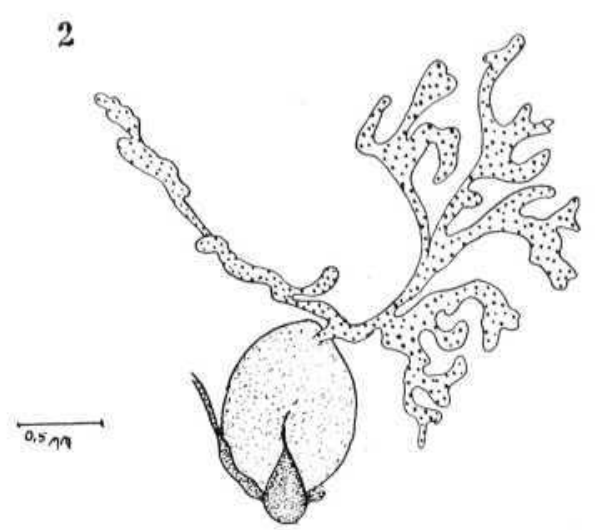

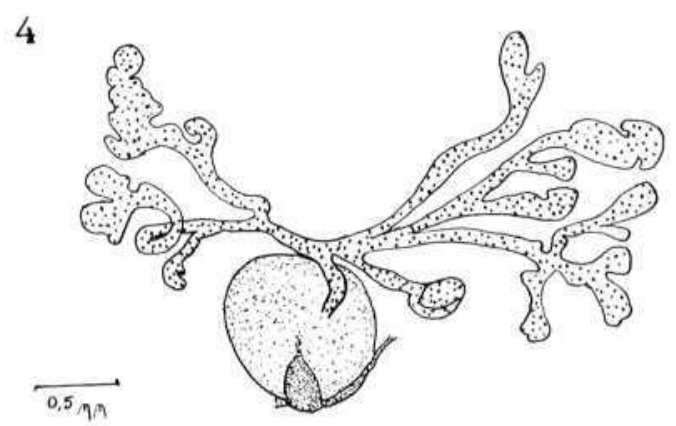
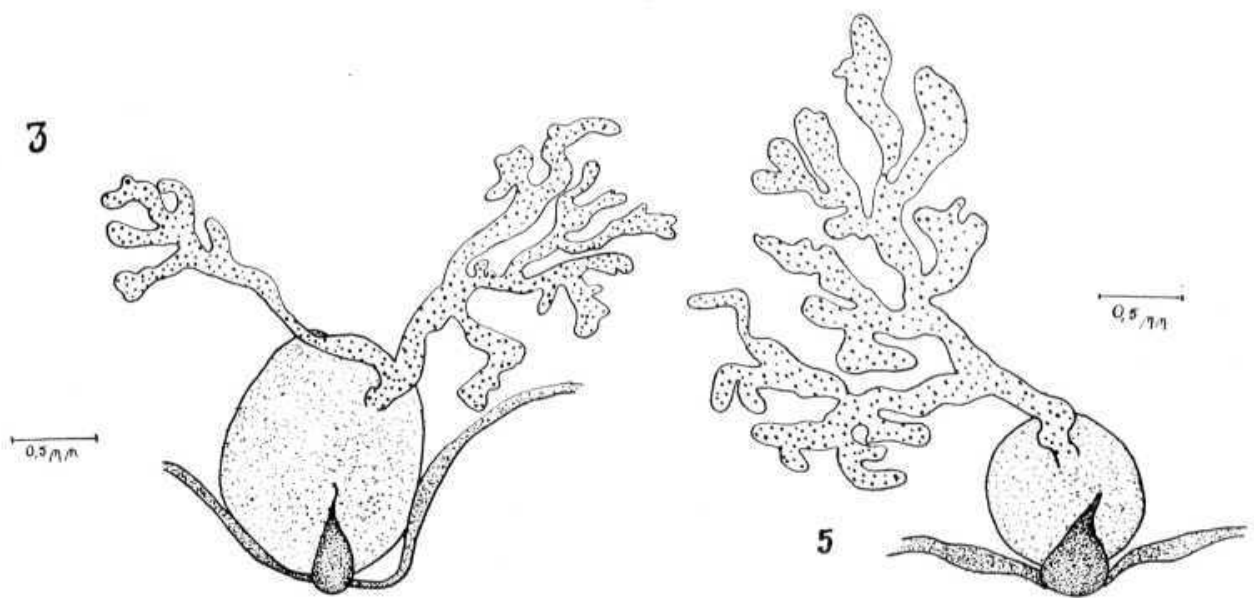
T. L. Araujo e Y. Gandra, Nova Capillaria $e$ observações Helmintológicas.
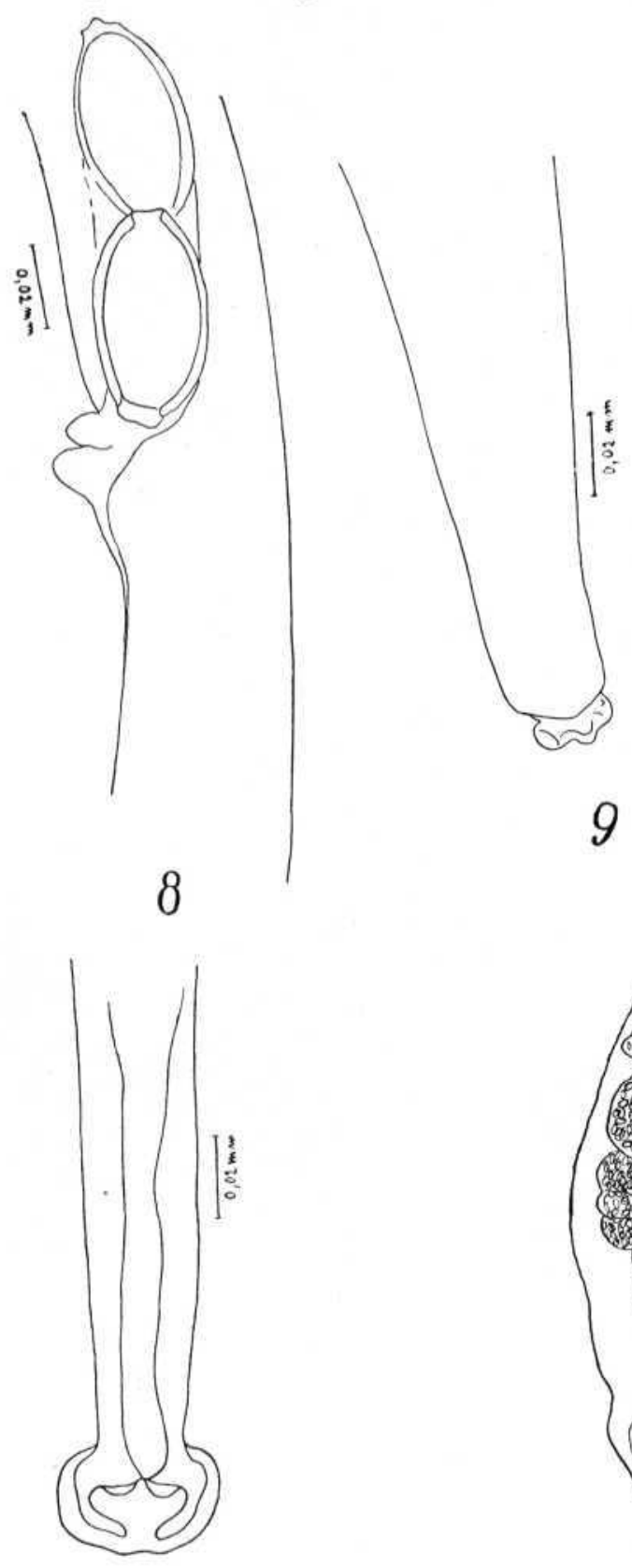

6
Rev. Fac. Med. Vet. S. Paulo, Vol, 2, fasc. 1

Est. VII
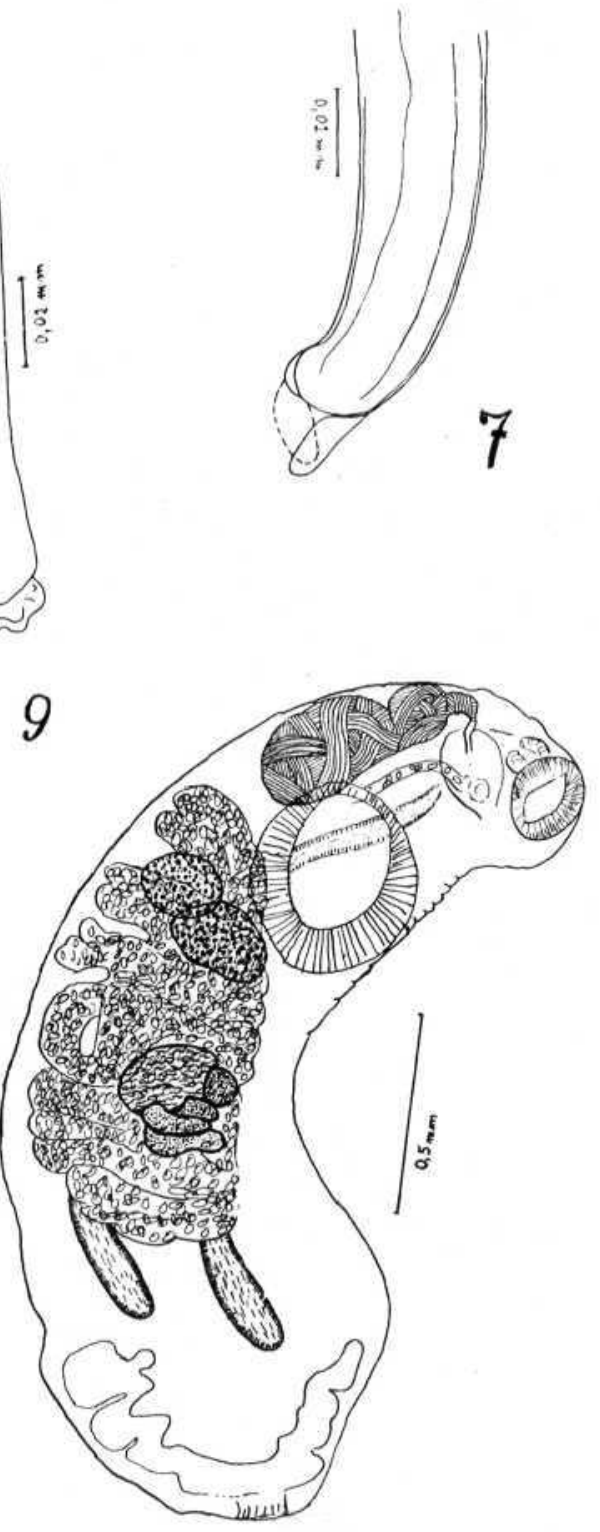